\title{
The Influence of Biomimetic Deposition Ca-P Coatings on the Release of Simvastatin from $\mathrm{TiO}_{2}$ Nanotube Array
}

\author{
Chunlin XIE ${ }^{\mathrm{a}}$, Haizhen $\mathrm{TANG}^{\mathrm{b}}$ and Xiufeng XIAO \\ College of Chemistry and Chemical Engineering, Fujian Normal University, Fuzhou 350117 \\ abiomaterials@qq.com, ${ }^{\text {b23446039@qq.com, }{ }^{c} x f x i a o @ f j n u . e d u . c n ~}$
}

\begin{abstract}
In order to improve the capacity of simvastatin and extend the time of the release of the drug, this experiment adopts bionic-deposition to decorate a layer of octacalcium phosphate (OCP) on the face of $\mathrm{TiO} 2$ nanotube array,and respectively discusses what are the appropriate parameters of octacalcium phosphate (OCP) can be generated. Experiments show that loading a layer of octacalcium phosphate can extend the time of the release of the drug. In addition, the presence of simvastatin on the $\mathrm{TiO} 2$ nanotube array will be a certain influence on the morphology of octacalcium phosphate. However, simvastatin can be dissolved into the bionic fluid by using bionic deposition. Therefore, by step concentration soaking and then using this method to load OCP with simvastatin can effectively improve the amount of simvastatin loaded and extend drug release
\end{abstract}

Keywords: $\mathrm{TiO} 2$ nanotube arrays; Biomimetic deposition; Simvastatin; Octacalcium phosphate

\section{Introduction}

The inertia of pure titanium can easily cause the failure of implant, so it is necessary to modify the surface of pure titanium, through the process of anodic oxidation to create a layer of $\mathrm{TiO}_{2}$ nanotube array can improve the biocompatibility of pure titanium. $\mathrm{TiO}_{2}$ nanotube loading simvastatin(SIM) can promote bone growth, which can promote the growth of bone tissue around replacement material. To increase the load of simvastatin and extend the releasing time of the drug, it is necessary to modify the surface of $\mathrm{TiO}_{2}$ nanotube array. By loading a layer of calcium phosphate on the surface and dissolve simvastatin into the reaction solution of calcium phosphate can increase the drug's loading. Calcium phosphate is familiar to the form of human's bone, especially like hydroxyapatite and octacalcium phosphate(OCP) are main component of human's body tissue, the existence of Ca-P salt on the surface of $\mathrm{TiO}_{2}$ nanotube array is in favor of the formation of new bone tissue around transplant material, also it is benefit to osseointegration between titanium replacement and new bone. Biomimetic Ca-P layer can improve the biocompatibility and modify the reactivity on the surface of implant, and increase the binding force between implant and bone tissue, which has been widely applied in dental implant. 
This experiment use biomimetic technique to load a layer of ca-p salt on the surface of $\mathrm{TiO}_{2}$ nanotube array to modify the nanotube. The main ingredients of Ca-P salt is OCP. Using degradative OCP to modify the surface of nanotube can prevent the explosive release of the drug, and let simvastatin to be released slowly with the degradation of Ca-P salt.

\section{Experiment Section}

\subsection{Pretreatment of Titanium.}

Slice pure titanium sheet into $10 \mathrm{~mm} \times 10 \mathrm{~mm}$, the area of anodic oxidation is $10 \mathrm{~mm} \times 10 \mathrm{~mm}$, then sanding and polishing until the surface of pure titanium sheet is smooth.Use ultrasonic with acetone to clean the greasy dirt on the surface for $15 \mathrm{~min}$, then use $4 \mathrm{wt} \% \mathrm{HF}-5 \mathrm{~mol} / \mathrm{L}$ $\mathrm{HNO}_{3}$ to do chemical polishing for $6 \mathrm{~s}$, use redistilled water to clean the surface, then ultrasonic cleaning for $10 \mathrm{~min}$. If the surface of the sheet is not clean enough, change water and use redistilled water to ultrasonic cleaning for $10 \mathrm{~min}$, dry to be stand by.

\subsection{Preparation of TiO2 Nanotube Array.}

Anodic oxidation is process in electrochemistry system,with the condition of water bath.Titanium sheet is used as anode, and large sheet of platinum sheet is used as cathode, two sheet is kept at the distance of $1 \mathrm{~cm} .0 .50 \mathrm{wt} \% \mathrm{NH}_{4} \mathrm{~F}+10 \mathrm{vol} \% \mathrm{H}_{2} \mathrm{O}$ glycerite is used as electrolyte solution. The power is supplied by DH1715A-5 DC stabilized power, the voltage is $60 \mathrm{~V}$, the whole experiment is processing with magnetic stirring and in the temperature of $30^{\circ} \mathrm{C}$. After 24 hours of anodic oxidation, the sample is taken out immediately and cleaned with redistilled water, then dry at the room temperature. Put amorphous $\mathrm{TiO}_{2}$ nanotubes separately at the temperature of $450{ }^{\circ} \mathrm{C}$ and $600{ }^{\circ} \mathrm{C}$ to calcin for $2 \mathrm{~h}$, then, it will become anatase and anatase/rutile form of $\mathrm{TiO}_{2}$, then use step concentration soaking with amorphous, anatase and anatase/rutile form of $\mathrm{TiO}_{2}$. To load SIM and proceed with controlled-release, take every group for five times and take mean value.

\subsection{Step Concentration Soaking.}

Soaking $\mathrm{TiO}_{2}$ nanotube orderly into absolute ethyl alcohol $(0 \mathrm{mg} / \mathrm{ml}), 1 \mathrm{mg} / \mathrm{ml}, 30 \mathrm{mg} / \mathrm{ml}$ $\mathrm{SIM}, 60 \mathrm{mg} / \mathrm{ml} \mathrm{SIM}$, and $100 \mathrm{mg} / \mathrm{ml}$ SIM for $2 \mathrm{~h}$ each, total $12 \mathrm{~h} . \mathrm{TiO}_{2}$ nanotubes which has been taken out from the lower concentration should be put into next drug solution of higher concentration instantly. As soon as the soaking is done take out and dry.

\subsection{Biomimetic Deposition OCP.}

The simulated body fluid with different concentration and different $\mathrm{pH}$ were shown in Table 1. First, put $\mathrm{TiO}_{2}$ nanotubes in SBF-A to react at the constant temperature $\left(37^{\circ} \mathrm{C}\right)$ for a while, then put into SBF-B to react at $37^{\circ} \mathrm{C}$. According to young's report[1], dissolve $41 \mathrm{mg}$ SIM into $1 \mathrm{ml} 95 \%$ ethanol and $1.5 \mathrm{ml} 0.1 \mathrm{M} \mathrm{NaOH}$ solution, then water bath at $50^{\circ} \mathrm{C}$ for $2 \mathrm{~h}$, use $0.1 \mathrm{~mol} \mathrm{HCl}$ to adjust $\mathrm{pH}$ to neutral, then use distilled water to add solution to $10 \mathrm{ml}$, prepare into concentrated solution of $10^{-2} \mathrm{M}$, save in the $-10^{\circ} \mathrm{C}$ refrigerator. Dilute SIM as required, make the concentration of SBF-B $10^{-5} \mathrm{M}$,then to further react. 
TABLE 1 ION CONCENTRATION OF SBF-A/SBF-B AND COMPARED WITH HUMAN BLOOD PLASMA

\begin{tabular}{|c|c|c|c|c|c|c|c|c|c|}
\hline Ions(mM) & PH & $\mathrm{Na}^{+}$ & $\mathrm{K}^{+}$ & $\mathrm{Ca}^{2+}$ & $\mathrm{Mg}_{+}^{2}$ & $\mathrm{HCO}_{3}$ & $\mathrm{Cl}^{-}$ & $\mathrm{HPO}_{3}{ }^{2}$ & $\mathrm{SO}_{4}{ }^{2}$ \\
\hline $\begin{array}{l}\text { Blood } \\
\text { Plasma }\end{array}$ & 7.4 & $\begin{array}{l}142.0 \\
0\end{array}$ & $\begin{array}{l}5.0 \\
0\end{array}$ & 2.50 & 1.50 & 27.00 & $\begin{array}{l}103.0 \\
0\end{array}$ & 1.00 & 0.50 \\
\hline SBF & 7.4 & $\begin{array}{l}142.0 \\
0\end{array}$ & $\begin{array}{l}5.0 \\
0\end{array}$ & 2.50 & 1.50 & 4.20 & $\begin{array}{l}148.0 \\
0\end{array}$ & 1.00 & 0.50 \\
\hline SBF-A & 5.5 & $\begin{array}{l}142.0 \\
0\end{array}$ & - & 2.50 & 1.50 & 4.20 & $\begin{array}{l}148.0 \\
0\end{array}$ & 1.00 & - \\
\hline 3SBF-A & 5.5 & $\begin{array}{l}426.0 \\
0\end{array}$ & - & 7.50 & 4.50 & 12.60 & $\begin{array}{l}444.0 \\
0\end{array}$ & 3.00 & - \\
\hline 5SBF-A & 5.5 & $\begin{array}{l}710.0 \\
0\end{array}$ & - & $\begin{array}{l}12.5 \\
0\end{array}$ & 7.5 & 21.00 & $\begin{array}{l}740.0 \\
0\end{array}$ & 5.00 & - \\
\hline SBF-B & 7.04 & $\begin{array}{l}142.0 \\
0\end{array}$ & - & 2.50 & - & - & $\begin{array}{l}148.0 \\
0\end{array}$ & 1.00 & - \\
\hline 3SBF-B & 7.04 & $\begin{array}{l}426.0 \\
0\end{array}$ & - & 7.50 & - & - & $\begin{array}{l}444.0 \\
0\end{array}$ & 3.00 & - \\
\hline 5SBF-B & 5.5 & $\begin{array}{l}710.0 \\
0\end{array}$ & - & $\begin{array}{l}12.5 \\
0\end{array}$ & - & - & $\begin{array}{l}740.0 \\
0 \\
\end{array}$ & 5.00 & - \\
\hline
\end{tabular}

\subsection{Release of Simvastatin.}

Soak $\mathrm{TiO}_{2}$ nanotube array which load SIM into $10 \mathrm{ml} \mathrm{pH}=7.4 \mathrm{PBS}$ solution at a $37^{\circ} \mathrm{C}$ thermostatic water bath oscillator, $0.5 \mathrm{ml}$ of supernatant liquid of the sample is collected in a period of time, then add same amount of fresh PBS solution. The release check experiment of SIM of the sample last for half a month, use ultraviolet spectrometry to detect it's absorbance at $239 \mathrm{~nm}$.

\subsection{Characterization of the Sample.}

Using X-ray diffraction (Philips X'Pert MPD, XRD) to analysis the phase of the sample, the excitation source is $\mathrm{Cu}$ and $K a$, the voltage is $40 \mathrm{kV}$, the current is $40 \mathrm{~mA}$, the step is $0.02^{\circ}$, scanning speed is $4 \% \mathrm{~min}$. UT1900 ultraviolet spectrometry to detect the absorbance of the solution.

\section{Results and Discussion}

\subsection{The Influence of the Structure of TiO2 Nanotube Array to the Formation of Ca-P Salt.}

As the Fig. 1 shows that amorphous $\mathrm{TiO}_{2}$ nanotubes array is more likely to form OCP than anatase phase or anatase/rutile phase. Curve a is for amorphous $\mathrm{TiO}_{2}$ nanotubes, Curve b is for the mixed phase of anatase/rutile. Curve $\mathrm{c}$ is for the phase of anatase, the characteristic peak of anatase appears at $\theta=25.2^{\circ}$, the characteristic peak of OCP appears at $\theta=26^{\circ}$.In addition, $b$ and $\mathrm{c}$ show that hydroxyapatite's characteristic peaks at $\theta=31.7^{\circ}$, Curve a shows hydroxyapatite's characteristic peaks from $\theta=31^{\circ}$ to $\theta=33^{\circ}$ and this peak has separated, it is because two kinds of substance's peak has overlapped, b and c appear hydroxyapatite's 
characteristic peaks at $\theta=31.7^{\circ}$,appears OCP 's characteristic peaks at $\theta=32.5^{\circ}$. It can be judged from $b$, c curve that the phase of anatase/rutile is more likely to form hydroxyapatite than OCP, there large amount of document has reported that it is easier for crystalline phase $\mathrm{TiO}_{2}$ nanotubes array to generate hydroxyapatite[2]. As result shows that anatase/rutile's crystalline phase is benefit for generate hydroxyapatite.

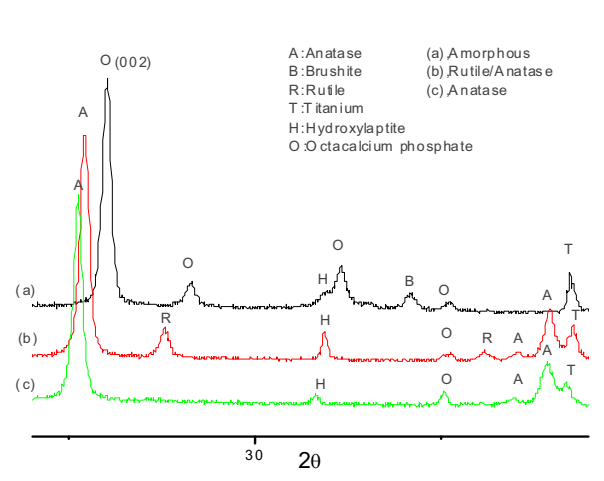

Fig.1 The effect of crystal phase of $\mathrm{TiO}_{2}$ nanotube array make on the type of Ca-P coating

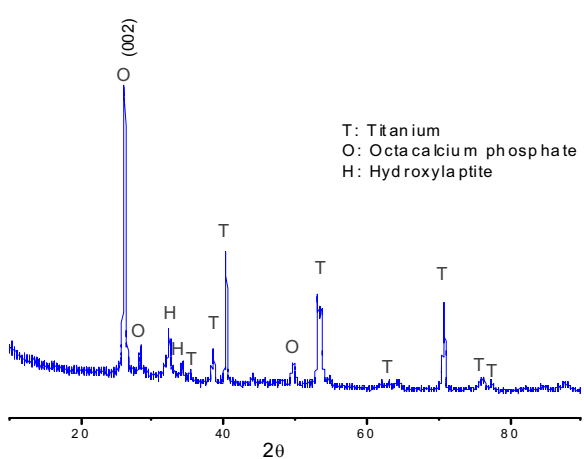

Fig. 2 The main composition of Ca-P coating is OCP. which prepared in the simulated body fluid $\mathrm{A}(\mathrm{pH}=5.5)$ for $48 \mathrm{~h}$ and simulated body fluid B $(\mathrm{pH}=7.05)$ for $36 \mathrm{~h}$.

\subsection{The Morphology and Structure of the Biomimetic Ca-P Salt.}

Put $\mathrm{TiO}_{2}$ nanotube array into 5 times SBF-A to react $48 \mathrm{~h}$, take out and clean with distilled water, then put it into 1 time SBF-B to react another 48h, Fig. 2 shows the XRD pattern of the bimimetic Ca-P coating. It appears that characteristic peak of $\mathrm{OCP}(002)$ at $\theta=26^{\circ}$ and $\theta=28.1^{\circ}$, hydroxyapatite and OCP has characteristic peak at $\theta=32^{\circ}$ and two substance is overlapped. But judging from the intense of the peak, the main ingredient of the biomimetic phase is OCP.

Although OCP is a compound Ca-P salt, but it has the effect to promote the growth of bone. Because the OCP is is degradative, if a drug can promote bone growth like SIM, can be dissolve into SBF-B to generate OCP together, then, with the degradation of OCP, SIM can be released into the sick bone, this can keep the drug to be released at the sick bone for a long period of time, so as to reach better therapeutic effect.

In addition, the concentration of $\mathrm{Ca}$ and $\mathrm{P}$ ion around the sick bone is high ,the human organism can produce hydroxyapatite itself to promote the formation and growth of the new bone. Since Ca-P salt gained by bionic method has little amount of hydroxyapatite that can not be degraded, this can provide crystal nucleus foundation for $\mathrm{Ca}$ and $\mathrm{P}$ ion to form hydroxyapatite, and benefit for the fast formation of hydroxyapatite at sick bone.

SEM photo below shows the morphology of Ca-P salt at shorter and longer reaction time. When the reaction time is shorter, the morphology of Ca-P salt is not orderliness, it first fill the orifice of $\mathrm{TiO}_{2}$ nanotube. As the Fig. 3a shows that as time increases, the amount of Ca-P salt in gradually increasing and accumulate at the surface of $\mathrm{TiO}_{2}$ nanotube array, and finally, the flaky Ca-P coat covers completely on the surface of $\mathrm{TiO}_{2}$ nanotube array, as the Fig. $3 b$ showed. 


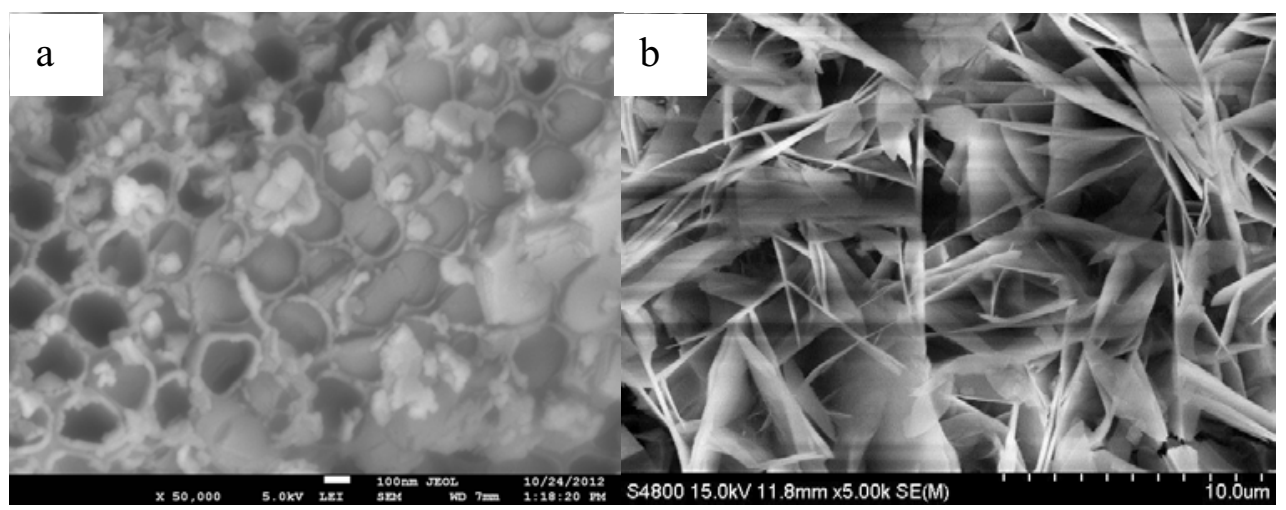

Fig. 3 The morphology of Ca-P coating: (a) reaction with a short time ; (b) reaction with a long time

\subsection{The Influence of Simvastatin in SBF-B on the Morphology of Ca-P Salt.}

To increase the load of SIM on the $\mathrm{TiO}_{2}$ nanotube array, this experiment dissolve SIM into SBF-B, to produce a certain thickness of Ca-P coating to accumulate on the surface of $\mathrm{TiO}_{2}$ nanotube array. Because the SBF-A is used to form Ca-P crystal nucleus, to form Ca-P crystal nucleus quickly, 5times SBF-A is chosen. Since the formation of crystal nucleus can not be effected, drug cannot be added into SBF-A.When it comes to growing step, a certain amount of SIM should be add into SBF-B. Maeda[3] gets the differentiation and growth situation of preosteoblast MC3T3-E1 in the different amount of SIM of nutrient solution that under the concentration of $10^{-7} \mathrm{M}$ SIM nutrient solution, it is best for the preosteoblast to differentiate and grow, the total amount of protein leve, alkaline phosphatase and osteocalcin is rather high. Consider the concentration of SIM in nutrient solution has been set, but when it comes to human body, with the degradation of Ca-P salt, the SIM which gradually released into the sick bone will be diluted because of the circulate of the body fluid, the concentration of SIM around sick bone can not reach $10^{-7} \mathrm{M}$,so it is necessary to raise the concentration of the SIM. This experiment add $10^{-5} \mathrm{M}$ of SIM into SBF-B, to deposit with Ca-P salt. Fig.4 shows the influence of SIM in SBF-B to the morphology of Ca-P salt . Fig.4 a, c, e shows the morphology of Ca-P salt is still sheet structure without adding SIM into SBF-B, this sheet structure grow vertically. But when adding $10^{-5} \mathrm{M}$ of SIM into SBF-B, as Fig. $4 \mathrm{~b}$, d,f shows, $\mathrm{Ca}-\mathrm{P}$ salt become thinner, the sheet structure become smaller, vertical sheet structure disappears and shows irregular, twisted and amorphous sheet structure. Comparing two photos below, adding SIM into SBF-B has bigger influence on the the morphology of Ca-P salt. 


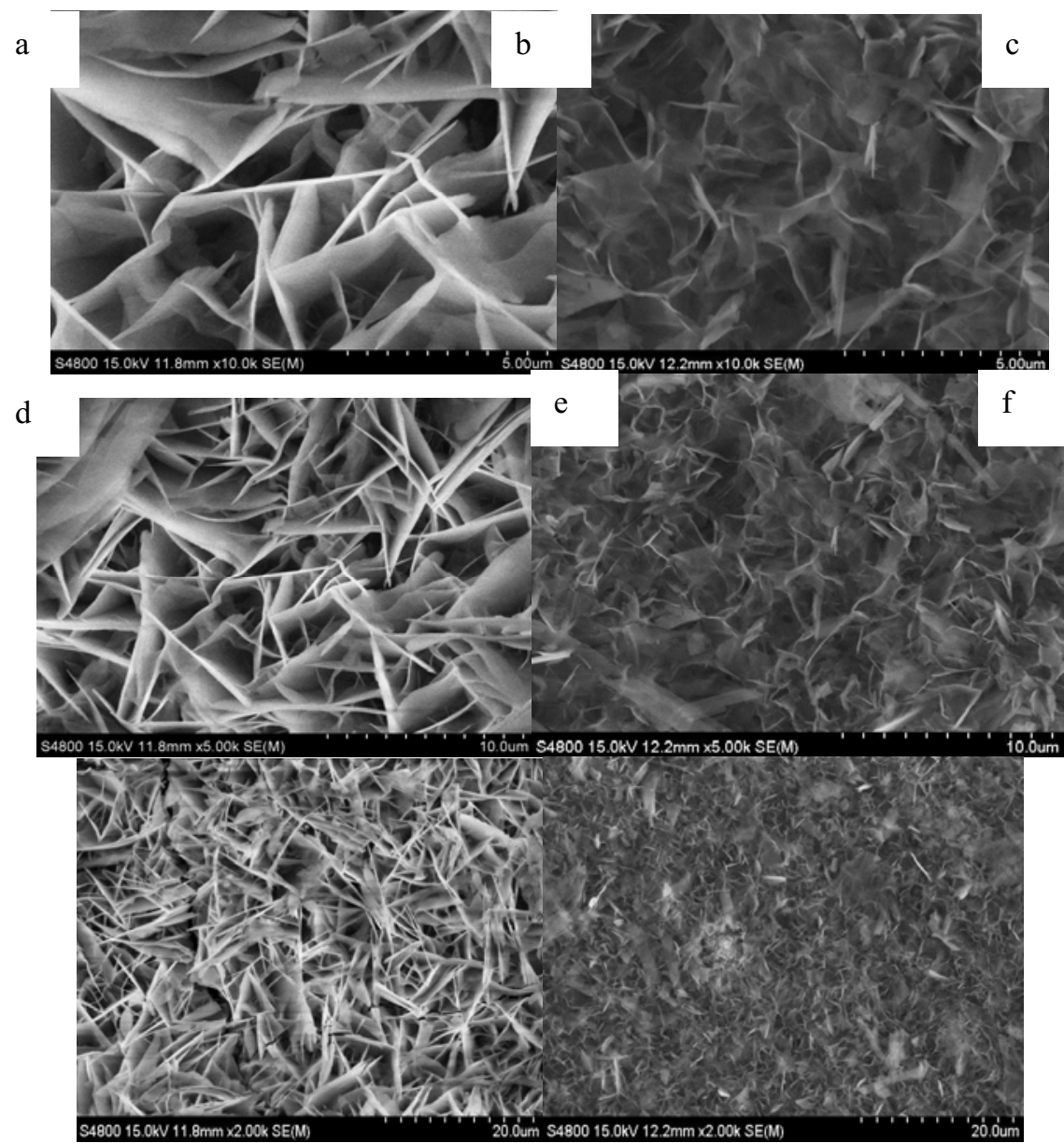

Fig. 4 The morhgology of the OCP under different magnification : (a),(c),(e) are the Ca-P coating prepared without simvastatin in simulated body fluid B ; (b),(d),(f) are the Ca-P coating prepared with simvastatin in simulated body fluid $\mathrm{B}$.

\subsection{The Influence of TiO2 Nanotube Array on the Load and Release of SIM after Deposit the Bimimetic Ca-P Salt.}

Fig. 5 shows the drug release after the Ca-P salt is modified, Curve a shows the release of amorphous $\mathrm{TiO}_{2}$ nanotube array which is soaked by SIM, Curve b shows the release of $\mathrm{TiO}_{2}$ nanotube array which has been soaked SIM once, then through bimimetic deposition with $10^{-5} \mathrm{M}$ dissolved into SBF-B. Judging from the release of modified nanotubes, the release does not increase per period, vice versa, it decline.

The possible reason as follows. First of all, the degradation speed of OCP is slow, so the amount of SIM released by Ca-P salt is limited. Secondly, the Ca-P salt formed by bionic deposition covers at the surface of nanotube. In some extent, it will affect the release of SIM in the nanotube, but there are gaps between the scale on the Ca-P salt, this allows SIM to release through the gaps of Ca-P salt. In a word, after biomimetic deposition, the amount of release in a period of time has been declined.

However, because SIM is loaded on nanotubes by step concentration soaking, and deposit SIM and Ca-P salt on the surface of nanotubes through bionic deposition, it load 
twice time of SIM through the process, so the total amount of drug loaded by modified nanotubes is much higher than unmodified nanotubes. Moreover, after being modified, the amount of release in a period of time has been declined, it means the release time is longer.

In addition, the release of SIM is still above $10^{-6} \mathrm{~g} / \mathrm{ml}$ after biomimetic deposition, the concentration is about $10^{-5} \mathrm{M}$. It is higher than the concentration of $10^{-7} \mathrm{M}$ as the document reported, it can effective solve the problem of inadequate drug amount around sick bone caused by dilution by systemic circulation in human body.

\section{Conclusion}

Anatase phase and mixed phase of anatase/rutile in biomimetic deposition, it produce hydroxyapatite but not OCP. The higher the concentration of SBF-B is , more hydroxyapatite can be produced. Under the same reaction condition, mixed phase of anatase/rutile is better for the growth of hydroxyapatite.Putting SIM into simulate body fluid to deposit with Ca-P salt, and combine with SIM which has been soaked by step concentration soaking, can increase the load amount. TiO2 nanotube array modified by biomimetic method, the load amount can be increased, it can extend the release time of the drug as well.

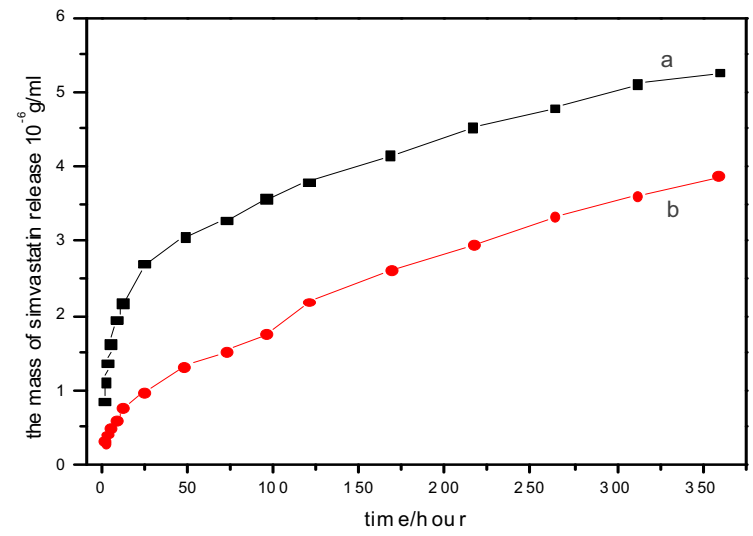

Fig.5 Compare to release of Simvastatin between untreated

$\mathrm{TiO}_{2}$ nanotube array and modified by biomimetic deposition OCP.

\section{References}

1. G.L.Yang, F.M. He, Biomechanical comparison of biomimetically and electrochemically deposited hydroxyapatite-coated porous titanium implants, Oral Maxillofac Surg, 68(2010)420-427.

2. L.Shi, Q. Yu, Inducing effects of annealing temperature and $\mathrm{TiO}_{2}$ structure on deposition of hydroxyapatite. Transactions of Materials and Heat Treatment, 31(2010) 44-47

3. T. Maeda, A. Matsunuma, T. Kawane, Simvastatin promotes osteoblast differentiation and mineralization in MC3T3-E1 cells, Biochem Biophys Res Commun, 280(2001)874-877. 